


\section{Proficiency test of detection of packaging material in bakery by-products 2019}

L.W.D. van Raamsdonk, C.P.A.F. Smits, B. Hedemann 
L.W.D. van Raamsdonk, C.P.A.F. Smits, B. Hedemann, 2020. Proficiency test of detection of packaging material in bakery by-products 2019. Wageningen, Wageningen Food Safety Research, WFSR report 2020.022. 20 pp.; 1 fig.; 2 tab.; 9 ref.

Project number: 1297388901

Project leader: Leo van Raamsdonk

This report can be downloaded for free at https://doi.org/10.18174/543274 or at www.wur.eu/foodsafety-research (under WFSR publications).

(C) 2020 Wageningen Food Safety Research, institute within the legal entity Wageningen Research Foundation. Hereinafter referred to as WFSR.

The client is allowed to publish or distribute the full report to third parties. Without prior written permission from WFSR it is not allowed to:

a) publish parts of this report;

b) use this report or title of this report in conducting legal procedures, for advertising, acquisition or other commercial purposes;

c) use the name of WFSR other than as the author of this report.

P.O. Box 230, 6700 AE Wageningen, The Netherlands, T +31 (0)317 4802 56, E info.wfsr@wur.nl, www.wur.eu/food-safety-research. WFSR is part of Wageningen University \& Research.

This report from WFSR has been produced with the utmost care. However, WFSR does not accept liability for any claims based on the contents of this report.

WFSR report 2020.022

Distribution list:

- International Association for Feeding stuff Analysis (IAG), Section Feeding stuff Microscopy (G. Frick, J. Vancutsem, R. Weiss, R. Krull-Wöhrmann)

- All participants of the proficiency test 


\section{Contents}

$\begin{array}{ll}\text { Summary } & 5\end{array}$

$\begin{array}{lll}1 & \text { Introduction } & 7\end{array}$

$\begin{array}{llr}2 & \text { Materials and methods } & 8\end{array}$

$\begin{array}{llr}3 & \text { Results } & 9\end{array}$

4 Discussion $r$

$\begin{array}{llr}5 & \text { Conclusion } & 13\end{array}$

$\begin{array}{llr}6 & \text { Recommendation } & 14\end{array}$

$\begin{array}{llr}7 & \text { Acknowledements } & 15\end{array}$

$\begin{array}{ll}\text { References } & 16\end{array}$

$\begin{array}{lll}\text { Annex } 1 & \text { Results by participant } & 17\end{array}$ 



\section{Summary}

A proficiency test (PT) was organised for the detection of packaging materials in bakery by-products intended to be used as feed ingredients. Two blind samples of a size of 250 grams at spike levels of $50 \mathrm{mg}$ and $250 \mathrm{mg}$ per sample were distributed to 29 participants. Four participants analysed only a part of the sample material, leaving 25 data points eligible for further evaluation. The evaluation of the results was carried out according to the principles of the Standard ISO 17043:2010 and the Quality Guidelines for visual research, in the framework of individual spiking of the samples. This specific procedure was chosen to avoid large inhomogeneity of a general batch as basis for the production of the PT samples, with the consequence that usual statistics such as Z-scores could not be applied or needed modified interpretations. Results of this PT have been compared with the first PT in 2016 ( $n=22$ participants, same spike levels). Altogether this provided the presence of four datasets. Blanks were not included in both PTs.

The average recovery for the $50 \mathrm{mg}$ level was $179 \%$, and $105 \%$ for the $250 \mathrm{mg}$ level in the 2019 PT. The maximum overestimations were $441 \%$ (50 mg) and $170 \%$ (250 mg), respectively. Symmetrical recovery intervals were chosen of $34 \%-166 \%$ for the $50 \mathrm{mg}$ level and $66 \%-134 \%$ for the $250 \mathrm{mg}$ level. A share of $80 \%$ of the results for the $250 \mathrm{mg}$ sample was achieved within the limits of the recovery interval. A considerable number of overestimations was reported for the $50 \mathrm{mg}$ level (12 participants, 48\%) in the 2019 PT. Notwithstanding the limitations of statistical parameters, a higher precision in 2019 compared to the 2016 datasets can be concluded based on the smaller interval of the results, visible in the minimum-maximum ranges, in the $95 \%$ confidence intervals and in the lower standard deviations. In all cases the distributions are skewed to the right, shown by the underestimations in only one dataset, lack of outliers below the Lower Confidence Level and skewness values (much) higher than zero.

The number of overestimations was the major cause of the lack of compliance with the uncertainty intervals. This might be due to either insufficient removal of water and fat from the selected particles of packaging material, and/or the selection of other particles mimicking the packaging material (specificity issue). The precise background of the overestimations needs further evaluation. False negatives were not reported in both the 2016 nor the 2019 version of the PT. The methods are applicable in the framework of enforcing a zero tolerance prohibition when transferring the observations to a compliant or non-compliant decision in relation to a threshold. Enforcement of an action limit could be possible from a level of $0.1 \%$ or higher in the view that the number of underestimations is very limited.

Specificity as issue in the methods needs further investigation in order to document the precise cause of the deviations. Documentation for precise identification of packaging material needs to be developed. 


\section{Introduction}

An important factor in circular agriculture is the reuse of former food products (FFP). This term applies to all products produced with the intention of human consumption. Withdrawal from this principal use can occur after production (factory), during storage and transport, or in the retail stage. In contrast to materials which result from the processing of primary commodities (e.g. oil-seed hulls and kernels, cereal by-products, pulp, etc.), these FFPs have to be unpacked in a range of cases. Regulation (EC) 767/2009 Annex III mentions zero tolerance for the presence of remnants of packaging material in FFPs. In practice, relatively low action limits were installed in member states (van Raamsdonk et al., 2011).

Several methods for the detection of packaging material have been developed, with the scope of bakery by-products (van Raamsdonk et al., 2012) or compound feed containing bakery by-products (Amato et al., 2017). The RIKILT method for bakery by-products was accepted as IAG method during the Autumn meeting of the IAG section Feed Microscopy in 2015. Subsequent plans were made to organise a proficiency test (PT) for this and comparable methods. This PT was held in 2016 and results indicated that a training was recommended. Such a training was organised during the annual meeting of IAG section Feed Microscopy in Uppsala in 2017. Training samples were distributed in 2018 to every interested member of IAG section Feed Microscopy. A second PT was organised during Autumn 2019. This report presents the results of the PT of 2019, with reflections on the 2016 results. 


\section{Materials and methods}

Samples were based on bakery by-products from practice. These materials have been sent to WFSR in the past and the contamination was determined by removing all visible parts of packaging material from the matrix. The detection limit, as established by WFSR (formerly RIKILT ${ }^{1}$; van Raamsdonk et al., 2012) is $0.004 \%$, which means that the remaining material is below that threshold. A sufficient amount of matrix material was mixed for preparing the samples for the PT. All packaging material selected from samples from the last ten years was stored by WFSR. Portions were selected of the required amount, with attention to a balanced composition of paper, tin foil, plastic and some other minor types. All samples were spiked on an individual basis. With matrix and packaging material from practice, these samples can be considered to represent the practical situation.

Recovery is calculated as

$$
R_{\%}=\frac{r_{i}}{s_{i}} * 100
$$

with $r_{i}$ as the amount of recovered material, and $s_{i}$ as the amount of spiked material for every individual sample at each of the two spike levels. The parameter $R_{\%}$ is derived from the percent difference $D_{\%}$, one of the possible parameters for evaluating results in proficiency testing (ISO 17043: 2010, Appendix B.3.1.3, paragraph b). The relationship can be described as $R_{\%}=D_{\%}+100 \%$. The results obtained from incomplete examination of the samples were excluded for evaluation. The recovery intervals applied are extracted from the Quality Guidelines for visual research (WFSR, in press). Symmetrical intervals were chosen of $34 \%-166 \%$ for the $50 \mathrm{mg}$ samples and $66 \%-134 \%$ for the $250 \mathrm{mg}$ level.

Additionally, the Lower and Upper Confidence Limits ( $L C L$ and UCL) are calculated from the set of results for each of the two samples based on the average and standard deviation of the percent recovery $R_{\%}$, as follows:

$$
L C L=u-1.96 * S D, \quad U C L=u+1.96 * S D
$$

The results as obtained in 2019 (this report) will be compared to the results of the 2016 proficiency test and the approach as applied in this report will be discussed.

\footnotetext{
1 The name RIKILT is used in this report for activities performed prior to June $1^{\text {st }}, 2019$, the date of the merger with another institute.
} 


\section{Results}

Raw results of the 2019 proficiency test are presented in Annex 1. A graphical representation is given in Figure 1. Results of four participants were based on incomplete examination of the sample material (participants 3, 12, 45 and 52, indicated in Annex 1 with yellow boxes) and were excluded from further analysis, leaving 25 data points applicable for further evaluation. In most results of these four participants, considerable deviations from the spike level were found. The one underestimation found in the entire set of results was reported by one of these four participants (participant 12).

The average recovery for the $50 \mathrm{mg}$ level was $179 \%$, and $105 \%$ for the $250 \mathrm{mg}$ level. The maximum overestimations were $441 \%(50 \mathrm{mg})$ and $170 \%(250 \mathrm{mg})$, respectively. Fourteen participants reported to have applied the RIKILT method or a highly comparable method. Another 11 participants applied a laboratory method.
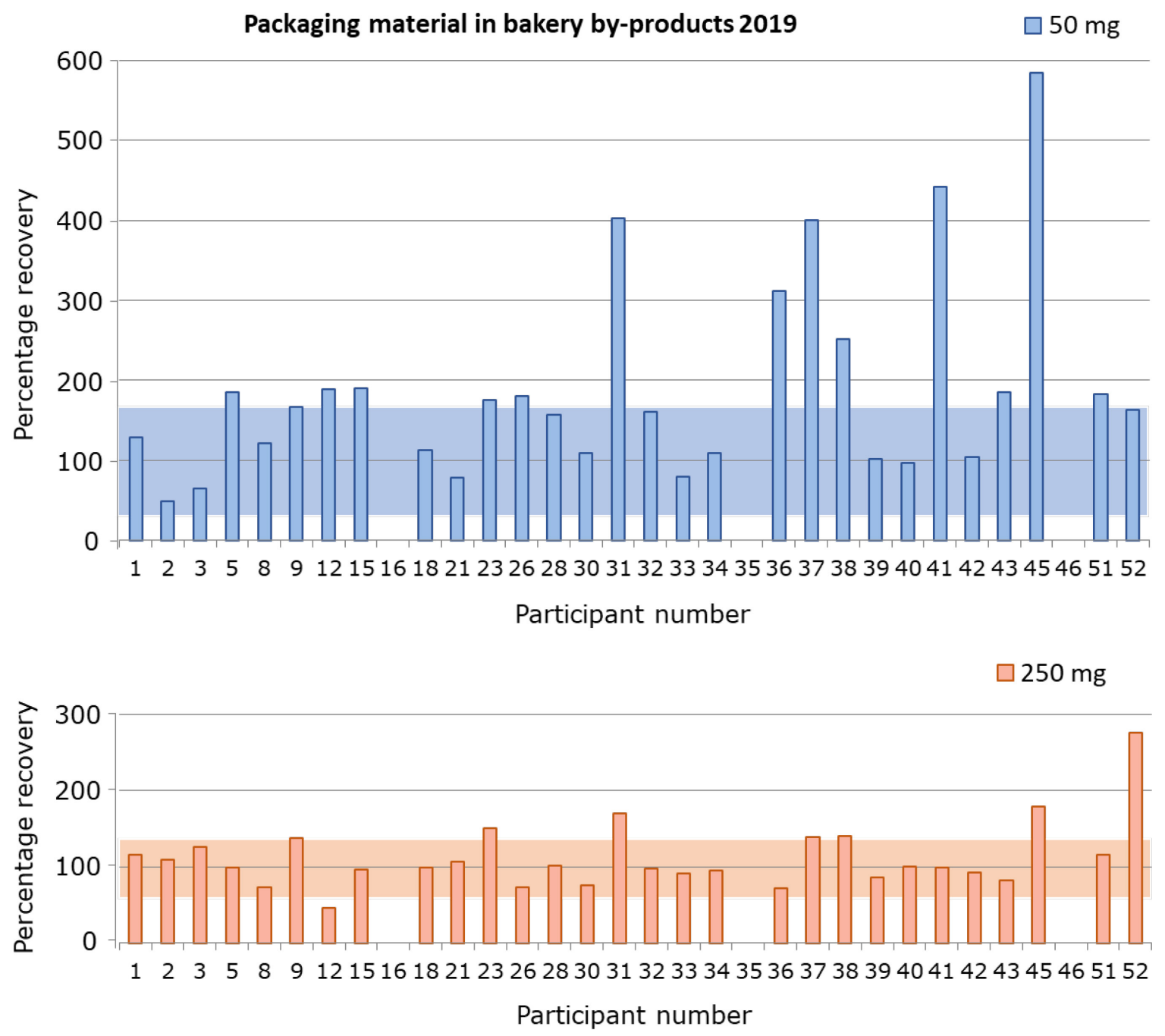

Figure 1 Overview of results per participant. Blue and orange boxes indicate the applicable recovery interval. 
Usual intervals applied for recovery in the spike range as applied in this study is $85-110 \%$ or $90-108 \%$ (AOAC, 2002; Codex Alimentarius, 2004). Experiments showed that larger intervals are applying to visual monitoring. Symmetrical intervals were chosen of $34 \%-166 \%$ for the $50 \mathrm{mg}$ samples and $66 \%$ $134 \%$ for the $250 \mathrm{mg}$ level. The overview in Figure 1 shows that a majority of participants reported values within limits, indicated by the coloured boxes in the graphs. Especially for the $250 \mathrm{mg}$ sample a result of $80 \%$ well performing participants was achieved (Table 1 ). A considerable number of overestimations was reported for the $50 \mathrm{mg}$ level (12 participants, 48\%). The background of the followed approach and a comparison with the 2016 results will be discussed in the next paragraph.

Table 1 Compliance of results for the applicable recovery interval. Number of eligible participants is 22 (2016) and 25 (2019).

\begin{tabular}{|c|c|c|c|c|c|}
\hline & interval & \multicolumn{2}{|c|}{$34 \%-166 \%$} & \multicolumn{2}{|c|}{$66 \%-134 \%$} \\
\hline & spike level & \multicolumn{2}{|c|}{$50 \mathrm{mg}$} & \multicolumn{2}{|c|}{$250 \mathrm{mg}$} \\
\hline & year & 2016 & 2019 & 2016 & 2019 \\
\hline n underestimating & & 0 & 0 & 3 & 0 \\
\hline n overestimating & & 4 & 12 & 2 & 5 \\
\hline
\end{tabular}




\section{Discussion}

A usual way to evaluate the results of a proficiency test is to calculate Z-scores (ISO, 2005, 2010). There are two reasons why this approach is not followed in this report. At first, Z-scores are calculated from the average recovery and the standard deviation of the reported results of the participants, under the assumption that all samples as analysed by the participants were taken from a homogenised batch, i.e. with exactly the same level of contamination. Every sample is a draw from the same population in statistical terms. In this PT, as usual for all PTs in the field of macroscopic visual research, every sample was spiked individually. Secondly, Z-scores are usually accepted as correct in the range of -1.96 to +1.96 times the SD, which by definition includes $95 \%$ of the results. The current results for the $50 \mathrm{mg}$ sample have an LCL of the $95 \%$ confidence interval of $-28 \%$ (Table 2), which would theoretically lead to acceptance of (erroneous) negative results. The highest result within the $95 \%$ confidence interval was a recovery of $192 \mathrm{mg}, 400 \%$ of the real value of $48 \mathrm{mg}$ for that sample (Annex 1, participant 37). The 2019 results for both samples show a prevailing overestimation, indicating a long right tail in the distribution of the sample results. The background of the followed strategy and the diversity of the results do not allow an evaluation using Z-scores. The larger dispersion of the results of the current proficiency test fits in the general picture of the performance of visual methods.

The current approach for evaluation was designed to be as close as possible to the requirements of ISO 17043:2010 (ISO, 2010). Besides Z-scores and comparable measures, this Standard provides the option of the parameter percent difference, which can be recalculated to the recovery percentage as used in this study. Additionally, a variety of different approaches for proficiency test organisation is foreseen, and insufficiently homogeneous materials can still be useful as proficiency test items, provided that the uncertainties of the assigned values or the evaluation of results take due account of this (ISO 17043:2010 Annex B.3.1.3 and ISO 13528:2005, Annex B). The possible uncertainty of the assigned value after batch mixing is compensated by using individual spiking of the samples. The diversity among subsamples of one sample as found in the analysis of weed seeds in bird feed and ergot sclerotia in cereals is caused by inhomogeneity of batches of visible units. Uncertainty intervals related to different spike levels can be extracted from this data, as presented and discussed in the Guidelines for Quality Assurance and Control of visual methods. After individual spiking, subsampling and inhomogeneity are not an issue, provided that the entire sample is analysed. Measurement uncertainty can have a variety of causes (Eurachem/CITAC guide, Appendix C; Ellison and Williams, 2012). Therefore, the limits for weight uncertainty in these Guidelines are applied here as best possible option for evaluation.

Based on this approach, a comparison of the 2019 dataset with the 2016 results can be made (data published in an unofficial report). A training option was provided in 2017 and labelled samples have been distributed in 2018. When applying identical weight intervals for both sets of results, a higher compliance for the $50 \mathrm{mg}$ level was found in 2016 compared to 2019, whereas an identical compliance was found for the $250 \mathrm{mg}$ level (Table 1). The non-compliant results were overestimations in all cases for three of the four datasets. Additional parameters have been calculated for testing this suggested decreasing performance at the lower levels (Table 2). For both spike levels, the range between the minimum and maximum reported recovery was lower in 2019 compared to 2016, resulting in a lower value for the standard deviation. The same trend was found for the LCL and UCL values showing a smaller 95\% confidence interval in 2019. The average recovery for the $50 \mathrm{mg}$ level was higher in 2019 compared to 2016. This observation, together with a lower percentage of compliance for the $50 \mathrm{mg}$ level in 2019 (Table 1), cannot be taken as decreasing tendency for accuracy and precision at that spike level. The shape of the distribution for all four sets of results is highly variable, as indicated by kurtosis and skewness. It can be argued whether these standard statistical parameters can be used to describe sufficiently the nature and background of the results for the detection of packaging material in bakery by-products. As argued, the data points do not belong to one population of results per year and spike level. Notwithstanding the limitations of statistical parameters, a higher precision in 2019 
can be concluded based on the smaller interval of the results, visible in the minimum-maximum intervals, in the LCL-UCL ranges and in the standard deviations (Table 2). In all cases the distributions are skewed to the right, shown in Figure 1, underestimations in only one dataset (Table 1), lack of outliers below the LCL value and skewness values (much) higher than 0 (Table 2). This tendency of skewness (overestimations) could be caused by two reasons: (a) insufficient drying and defatting of the selected packaging material, and (b) additional selection of material from the matrix together with the correctly identified packaging material. The latter would be a specificity problem.

Table 2 Recovery statistics in \% after exclusion of results based on incomplete sample examination. SD: Standard Deviation. LCL: Lower Confidence Limit and UCL: Upper Confidence Limit of the $95 \%$ confidence interval of the percentage recovery.

\begin{tabular}{|c|c|c|c|c|c|}
\hline & \multirow{2}{*}{$\begin{array}{r}\text { spike level } \\
\text { year }\end{array}$} & \multicolumn{2}{|c|}{$50 \mathrm{mg}$} & \multicolumn{2}{|c|}{$250 \mathrm{mg}$} \\
\hline & & 2016 & 2019 & 2016 & 2019 \\
\hline & $n=$ & 22 & 25 & 22 & 25 \\
\hline maximum & & $655 \%$ & $441 \%$ & $218 \%$ & $170 \%$ \\
\hline average & & $156 \%$ & $179 \%$ & $98 \%$ & $105 \%$ \\
\hline LCL & & $-119 \%$ & $-28 \%$ & $17 \%$ & $55 \%$ \\
\hline UCL & & $431 \%$ & $386 \%$ & $179 \%$ & $155 \%$ \\
\hline outliers ( $\mathrm{n}$ below LCL) & & 0 & 0 & 0 & 0 \\
\hline outliers (n over UCL) & & 1 & 4 & 2 & 3 \\
\hline Kurtosis & & 7.4 & 1.2 & 2.9 & 9.1 \\
\hline
\end{tabular}

The tested methods are intended to monitor the zero tolerance measure for packaging material in feedings stuffs (Regulation (EC) 767/2009, Annex II). Basically a quantitative result is not required for enforcement of a zero tolerance prohibition. False negative results were not reported for both editions of the PT on packaging materials, resulting in correct qualitative results in all cases. The sample sets of both PTs did not consist of a blank sample, which means that data on false positives is lacking. However, action limits are applied in practice, e.g. 0.15\% (van Raamsdonk et al., 2011). Considering this action limit, no results exceeding this level (1500 ppm) have been reported for the $50 \mathrm{mg}$ spike level $(0.02 \%)$. For the $250 \mathrm{mg}$ spike level $(0.1 \%)$, two out 22 results and two out of 25 results in the 2016 and the 2019 dataset, respectively, have been reported to exceed $1500 \mathrm{ppm}$. These results underline the need to explore further possible specificity issues. 


\section{Conclusion}

Two identical PTs have been organised in 2016 and in 2019, with intermediate training options consisting of non-blind samples at the same spike levels (50 mg and $250 \mathrm{mg}$ ) in 2017 and 2018. Since better insight has been gained in the evaluation of PT results since the 2016 PT, these results are re-evaluated and compared with the 2019 set. An increase in precision appeared to be achieved. Lack of compliance with the uncertainty intervals was predominantly due to overestimations. This might be caused by either insufficient removal of water and fat from the selected particles of packaging material, and/or the selection of other particles mimicking the packaging material (specificity issue). The precise background of the overestimations needs further evaluation. False negatives were not reported in both the 2016 nor the 2019 version of the PT. The methods are fit for purpose when transferring the observations to a qualitative result, which is suitable in the framework of enforcing a zero tolerance prohibition. Enforcement of an action limit could be possible from a level of $0.1 \%$ and higher in the view that the number of underestimations is very limited. 


\section{Recommendation}

Specificity as issue in the methods needs further investigation in order to document the precise cause of the deviations. A new PT is needed including one or more blank samples in combination with precise examination by an independent expert of the materials selected. It is important to apply a method which includes sufficient dehydration and defatting. The latter is important for the specific matrix with a relatively high fat content.

Documentation for precise identification of packaging material needs to be developed.

A further development of performance criteria is required for visual monitoring methods in order to facilitate the development of these methods for support to circular agriculture. 


\section{$7 \quad$ Acknowledements}

The board of IAG section Feeding Stuff Microscopy (G. Frick (Agroscope, Posieux), J. Vancutsem (FAVV, Tervuren), R. Weiss (AGES, Vienna), R. Krull-Wöhrmann (CVUA-RRW, Krefeld)) supported this study as advisory board. E. Reiter (AGES, Vienna) and H. Marescot (Service Commun des Laboratoires - Laboratoire de Rennes) were involved in the external review process. Their contributions are greatly acknowledged. Thanks to colleagues M. van Iersel and D. Beaujean for the internal WFSR review procedure. 


\section{References}

Amato, G., R. Desiato, T. Giovannini, L. Pinotti, M. Tretola, M. Gili \& D. Marchis, 2017. Gravimetric quantitative determination of packaging residues in feed from former food. Food Additives \& Contaminants: Part A, 34:8: 1446-1450, DOI: 10.1080/19440049.2017.1337277.

AOAC, 2002. Appendix D: Guidelines for collaborative study procedures to validate characteristics of a method of analysis.

Codex Alimentarius, 2004. Guidelines on measurement uncertainty. CAC/GL 54-2004.

Ellison, S. L. R. and A. Williams, (Eds), 2012. Eurachem/CITAC guide: Quantifying Uncertainty in Analytical Measurement, Third edition. ISBN 978-0-948926-30-3. Available from www.eurachem.org.

ISO, 2005. ISO 13528:2005. Statistical methods for use in proficiency testing by interlaboratory comparisons. International Standard Organisation, Geneva: ISO 13528:2005(E).

ISO, 2010. ISO/IEC 17043:2010. Conformity assessment - General requirements for proficiency testing. CEN/CENELEC, Brussels: Ref. No. EN ISO/IEC 17043:2010 E.

Pocklington, W.D., 1990. Harmonized protocols for the adoption of standardized analytical methods and for the presentation of their performance characteristics. Pure \& Appl. Chern., Vol. 62, No. 1, pp. 149-162.

Raamsdonk, L.W.D. van, R. Rijk, G.P.J. Schouten, W. Mennes, G.A.L. Meijer, A.F.B. van der Poel, and J. de Jong, 2011. A risk evaluation of traces of packaging materials in former food products intended as feed materials. Report 2011.002, RIKILT, Wageningen, pp. 69. http://edepot.wur.nl/171617

Raamsdonk, L.W.D. van, V. Pinckaers, J. Vliege, H. van Egmond, 2012. Examination of packaging materials in bakery products. A validated method for detection and quantification.

Report 2012.007, RIKILT, Wageningen, pp. 20.

http://edepot.wur.nl/240039 


\section{Annex 1 Results by participant}

$50 \mathrm{mg}$ sample. Every sample had a total weight of $250 \pm 1$ grams. Results within the recovery limits $34 \%-166 \%$ in green cells. Examination of a part of the entire sample is indicated by yellow cells.

\begin{tabular}{|c|c|c|c|c|c|c|}
\hline $\begin{array}{l}2019 \\
\text { lab nr }\end{array}$ & $\begin{array}{l}\text { sample A } \\
\mathrm{nr}\end{array}$ & $\begin{array}{l}\text { Analysed amount } \\
\text { (gram) }\end{array}$ & $\begin{array}{l}\text { Added } \\
\mathrm{mg}\end{array}$ & $\begin{array}{l}\text { Detected } \\
\mathrm{mg}\end{array}$ & Recovery & Comments \\
\hline 1 & 1304 & 249.87 & 50 & 64 & $128 \%$ & $\begin{array}{l}\text { aluminium foil, paper+fiber, and plastic in both } \\
\text { samples }\end{array}$ \\
\hline 2 & 1318 & 249.75 & 46 & 22.1 & $48 \%$ & plastic foil, plastic pieces, pieces of printed paper \\
\hline 3 & 1339 & 100 & 20 & 13 & $65 \%$ & soft plastic, paper, aluminium foil \\
\hline 5 & 1332 & 250 & 49 & 90.4 & $184 \%$ & plastic, aluminium foil; $32,9 \mathrm{mg}$ stones \\
\hline 8 & 1325 & 249.4 & 49 & 59.3 & $121 \%$ & \\
\hline 9 & 1311 & 248.1 & 54 & 89.9 & $166 \%$ & plastic, paper, aluminium \\
\hline 12 & 1297 & 50 & 10 & 18.9 & $189 \%$ & \\
\hline 15 & 1283 & 249.07 & 51 & 97 & $190 \%$ & \\
\hline 16 & 1276 & 250.73 & 49 & & & \\
\hline 18 & 1255 & 243 & 50 & 56.5 & $113 \%$ & $\begin{array}{l}\text { paper fibers, carton, plastic particles, plastic film, } \\
\text { aluminum foil }\end{array}$ \\
\hline 21 & 1262 & 248.00 & 51 & 40 & $78 \%$ & \\
\hline 23 & 1290 & 249.57 & 48 & 84.3 & $176 \%$ & aluminium foil, paper residues, soft plastic \\
\hline 26 & 1192 & 250.00 & 52 & 93.8 & $180 \%$ & plastic, theads, aluminium foil \\
\hline 28 & 1220 & 249.22 & 51 & 80.2 & $157 \%$ & \\
\hline 30 & 1227 & 248.51 & 55 & 60 & $109 \%$ & \\
\hline 31 & 1269 & 250.00 & 51 & 205 & $402 \%$ & \\
\hline 32 & 1178 & 250.00 & 48 & 77 & $160 \%$ & \\
\hline 33 & 1185 & 248.65 & 55 & 43.8 & $80 \%$ & \\
\hline 34 & 1213 & 248.00 & 52 & 56.8 & $109 \%$ & \\
\hline 35 & 1206 & 250.65 & 52 & & & \\
\hline 36 & 1248 & 256.60 & 50 & 156 & $312 \%$ & \\
\hline 37 & 1234 & 247.90 & 48 & 192 & $400 \%$ & \\
\hline 38 & 1241 & 243.10 & 55 & 138.5 & $252 \%$ & Plastics, aluminium foils, paper \\
\hline 39 & 1199 & 249.03 & 50 & 50.6 & $101 \%$ & Plastic, tin foil and paper. \\
\hline 40 & 1129 & 248.50 & 52 & 50 & $96 \%$ & \\
\hline 41 & 1115 & 249.73 & 53 & 233.95 & $441 \%$ & \\
\hline 42 & 1171 & 249.12 & 55 & 56.8 & $103 \%$ & \\
\hline 43 & 1164 & 255.00 & 54 & 100.1 & $185 \%$ & Cardboard, plastic, Aluminum \\
\hline 45 & 1136 & 201.30 & 42 & 245.2 & $584 \%$ & \\
\hline 46 & 1122 & 250.12 & 53 & & & \\
\hline 51 & 1143 & 238.69 & 50 & 91.1 & $182 \%$ & \\
\hline 52 & 1150 & 99.38 & 21 & 34.2 & $163 \%$ & \\
\hline
\end{tabular}


$250 \mathrm{mg}$ sample. Every sample had a total weight of $250 \pm 1$ grams. Results within the recovery limits $66 \%-134 \%$ in green cells. Examination of a part of the entire sample is indicated by yellow cells.

\begin{tabular}{|c|c|c|c|c|c|c|}
\hline $\begin{array}{l}2019 \\
\text { lab nr }\end{array}$ & $\begin{array}{l}\text { sampl } \\
\mathrm{nr}\end{array}$ & $\begin{array}{l}\text { Analysed amount } \\
\text { (gram) }\end{array}$ & $\begin{array}{l}\text { Added } \\
\mathrm{mg}\end{array}$ & $\begin{array}{l}\text { Detected } \\
\mathrm{mg}\end{array}$ & Recovery & Comments \\
\hline 1 & 1165 & 250.13 & 250 & 290 & $116 \%$ & $\begin{array}{l}\text { aluminium foil, paper+fiber, and plastic in both } \\
\text { samples }\end{array}$ \\
\hline 2 & 1151 & 249.75 & 250 & 271.4 & $109 \%$ & $\begin{array}{l}\text { plastic foil, plastic pieces, pieces of printed paper, } \\
\text { metall pieces }\end{array}$ \\
\hline 3 & 1179 & 100.00 & 99 & 124 & $125 \%$ & soft plastic, hard plastic, paper, aluminium foil \\
\hline 5 & 1158 & 250.00 & 248 & 244.5 & $99 \%$ & paper, plastic \\
\hline 8 & 1172 & 250.40 & 247 & 179.4 & $73 \%$ & \\
\hline 9 & 1186 & 248.30 & 254 & 349.4 & $138 \%$ & plastic, paper, aluminium \\
\hline 12 & 1193 & 50.00 & 50 & 23.1 & $46 \%$ & \\
\hline 15 & 1228 & 250.87 & 249 & 239 & $96 \%$ & \\
\hline 16 & 1235 & 250.52 & 253 & & & \\
\hline 18 & 1214 & 243.00 & 251 & 249.4 & $99 \%$ & $\begin{array}{l}\text { paper fibers, carton, plastic particles, plastic film, } \\
\text { aluminum foil }\end{array}$ \\
\hline 21 & 1221 & 249.00 & 249 & 264 & $106 \%$ & \\
\hline 23 & 1200 & 250.31 & 248 & 373 & $150 \%$ & aluminium foil, paper residues, soft plastic \\
\hline 26 & 1207 & 250.00 & 248 & 180.3 & $73 \%$ & plastic, threads, aluminium foil, glass \\
\hline 28 & 1249 & 250.03 & 255 & 257.4 & $101 \%$ & \\
\hline 30 & 1242 & 241.85 & 254 & 192 & $76 \%$ & \\
\hline 31 & 1319 & 250.00 & 248 & 421 & $170 \%$ & \\
\hline 32 & 1298 & 250.00 & 251 & 246 & $98 \%$ & staple (weighing $42 \mathrm{mg}$ ) \\
\hline 33 & 1305 & 248.65 & 248 & 225.9 & $91 \%$ & \\
\hline 34 & 1263 & 249.00 & 252 & 239.5 & $95 \%$ & \\
\hline 35 & 1256 & 249.77 & 252 & & & \\
\hline 36 & 1312 & 253.70 & 254 & 182 & $72 \%$ & \\
\hline 37 & 1291 & 245.81 & 250 & 347 & $139 \%$ & \\
\hline 38 & 1270 & 245.70 & 250 & 351.5 & $141 \%$ & Plastics, aluminium foils, paper \\
\hline 39 & 1277 & 246.68 & 252 & 217.4 & $86 \%$ & Plastic, tin foil and paper. \\
\hline 40 & 1284 & 248.55 & 250 & 250 & $100 \%$ & \\
\hline 41 & 1333 & 249.09 & 255 & 252.29 & $99 \%$ & \\
\hline 42 & 1326 & 249.59 & 255 & 234.1 & $92 \%$ & \\
\hline 43 & 1340 & 255.00 & 255 & 209.6 & $82 \%$ & Cardboard, plastic, Aluminum \\
\hline 45 & 1347 & 200.40 & 199 & 356.3 & $179 \%$ & \\
\hline 46 & 1354 & 250.30 & 254 & & & \\
\hline 51 & 1361 & 248.81 & 254 & 292 & $115 \%$ & \\
\hline 52 & 1368 & 89.60 & 91 & 250.3 & $275 \%$ & \\
\hline
\end{tabular}




\section{Declaration of the type of method applied.}

\begin{tabular}{|c|c|c|}
\hline $\begin{array}{l}2019 \\
\text { lab nr }\end{array}$ & $\begin{array}{l}\text { Read the ring test } \\
\text { Instructions }\end{array}$ & $\begin{array}{l}\text { Detection } \\
\text { Method }\end{array}$ \\
\hline 1 & Yes & RIKILT method report 2012.007 \\
\hline 2 & Yes & own laboratory method \\
\hline 3 & Yes & own laboratory method \\
\hline 5 & Yes & VDLUFA III. 30.9, Manuscript 2018-04 and VDLUFa III, 30.1 (Sample Preparing) \\
\hline 8 & Yes & own laboratory method \\
\hline 9 & Yes & own laboratory method \\
\hline \multicolumn{3}{|r|}{ ( } \\
\hline 15 & Yes & RIKILT method report 2012.007 \\
\hline \multicolumn{3}{|l|}{16} \\
\hline 18 & Yes & RIKILT method report 2012.007 \\
\hline 21 & Yes & own laboratory method \\
\hline 23 & Yes & own laboratory method \\
\hline 26 & Yes & RIKILT method report 2012.007 \\
\hline 28 & Yes & own laboratory method \\
\hline 30 & Yes & RIKILT method report 2012.007 \\
\hline 31 & Yes & RIKILT method report 2012.007 \\
\hline 32 & Yes & RIKILT method report 2012.007 \\
\hline 33 & Yes & RIKILT method report 2012.007 \\
\hline 34 & Yes & RIKILT method report 2012.007 \\
\hline \multicolumn{3}{|l|}{35} \\
\hline 36 & Yes & RIKILT method report 2012.007 \\
\hline 37 & Yes & RIKILT method report 2012.007 \\
\hline 38 & Yes & own laboratory method \\
\hline 39 & Yes & own laboratory method \\
\hline 40 & Yes & own laboratory method; close to RIKILT method \\
\hline 41 & Yes & RIKILT method report 2012.007 \\
\hline 42 & Yes & RIKILT method report 2012.007 \\
\hline 43 & Yes & own laboratory method \\
\hline 45 & Yes & RIKILT method report 2012.007 \\
\hline \multicolumn{3}{|l|}{46} \\
\hline 51 & Yes & own laboratory method \\
\hline 52 & Yes & own laboratory method; close to RIKILT method \\
\hline
\end{tabular}


Wageningen Food Safety Research

P.O. Box 230

6700 AE Wageningen

The Netherlands

T +31 (0)317480256

www.wur.eu/food-safety-research

WFSR report 2020.022
The mission of Wageningen University \& Research is "To explore the potential of nature to improve the quality of life". Under the banner Wageningen University \& Research, Wageningen University and the specialised research institutes of the Wageningen Research Foundation have joined forces in contributing to finding solutions to important questions in the domain of healthy food and living environment. With its roughly 30 branches, 6,500 employees (5,500 fte) and 12,500 students, Wageningen University \& Research is one of the leading organisations in its domain. The unique Wageningen approach lies in its integrated approach to issues and the collaboration between different disciplines. 



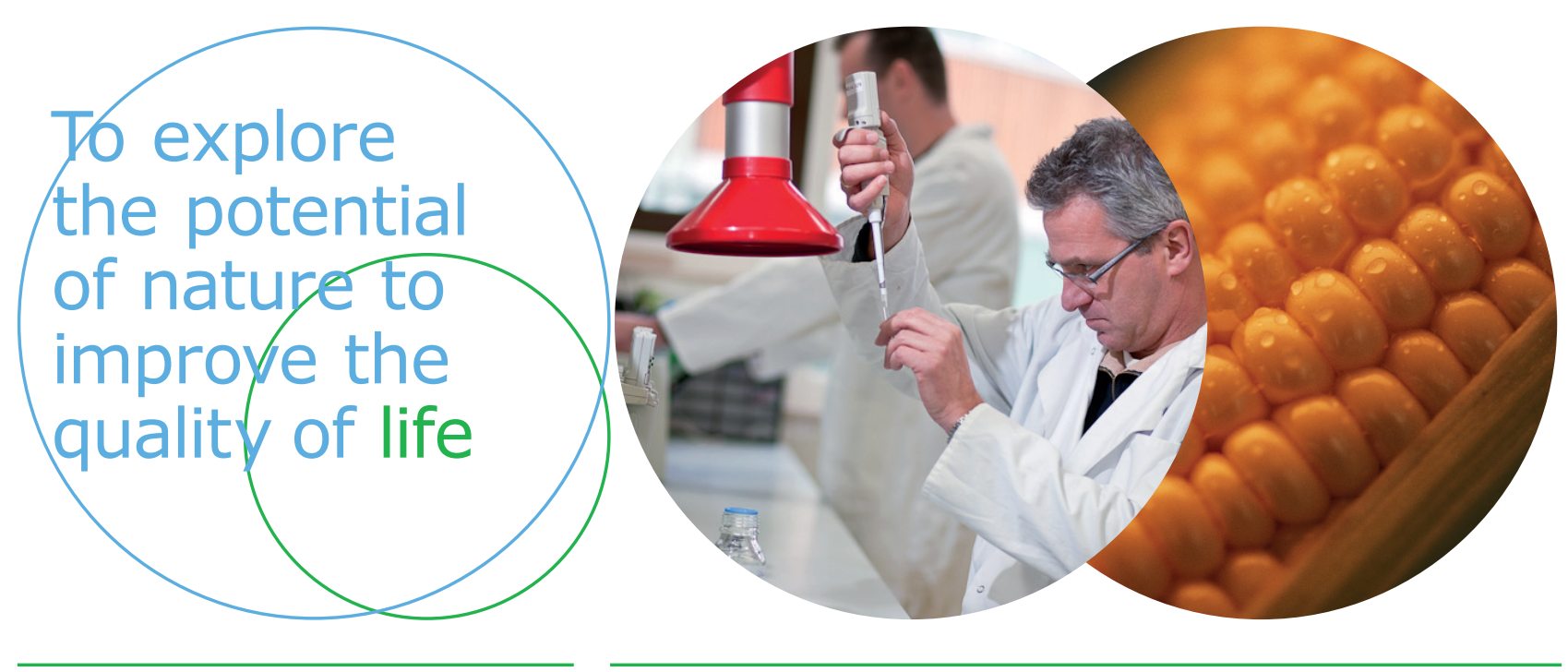

Wageningen Food Safety Research P.O. Box 230

6700 AE Wageningen

The Netherlands

T +31 (0)317480256

www.wur.eu/food-safety-research

WFSR report 2020.022
The mission of Wageningen University \& Research is "To explore the potential of nature to improve the quality of life". Under the banner Wageningen University $\&$ Research, Wageningen University and the specialised research institutes of the Wageningen Research Foundation have joined forces in contributing to inding solutions to important questions in the domain of healthy food and living environment. With its roughly 30 branches, 6,500 employees (5,500 fte) and 12,500 students, Wageningen University \& Research is one of the leading organisations in its domain. The unique Wageningen approach lies in its integrated approach to issues and the collaboration between different disciplines. 